ACCEPTED MANUSCRIPT

\title{
Design and development of a heatsink for thermo-electric power harvesting in aerospace applications
}

To cite this article before publication: Salvatore boccardi et al 2018 Smart Mater. Struct. in press https://doi.org/10.1088/1361-665X/aacbac

\section{Manuscript version: Accepted Manuscript}

Accepted Manuscript is "the version of the article accepted for publication including all changes made as a result of the peer review process, and which may also include the addition to the article by IOP Publishing of a header, an article ID, a cover sheet and/or an 'Accepted

Manuscript' watermark, but excluding any other editing, typesetting or other changes made by IOP Publishing and/or its licensors"

This Accepted Manuscript is @ 2018 IOP Publishing Ltd.

During the embargo period (the 12 month period from the publication of the Version of Record of this article), the Accepted Manuscript is fully protected by copyright and cannot be reused or reposted elsewhere.

As the Version of Record of this article is going to be / has been published on a subscription basis, this Accepted Manuscript is available for reuse under a CC BY-NC-ND 3.0 licence after the 12 month embargo period.

After the embargo period, everyone is permitted to use copy and redistribute this article for non-commercial purposes only, provided that they adhere to all the terms of the licence https://creativecommons.org/licences/by-nc-nd/3.0

Although reasonable endeavours have been taken to obtain all necessary permissions from third parties to include their copyrighted content within this article, their full citation and copyright line may not be present in this Accepted Manuscript version. Before using any content from this article, please refer to the Version of Record on IOPscience once published for full citation and copyright details, as permissions will likely be required. All third party content is fully copyright protected, unless specifically stated otherwise in the figure caption in the Version of Record.

View the article online for updates and enhancements. 


\title{
Design and development of a heatsink for thermo-electric power harvesting
}

\section{in aerospace applications}

\author{
Salvatore Boccardi, Francesco Ciampa, Michele Meo \\ Department of Mechanical Engineering, University of Bath, Claverton Down BA2 7AY, UK
}

\begin{abstract}
In recent years, the growing interest of aerospace companies in wireless structural health monitoring systems has led to the research of new energy efficient sources and power harvesting solutions. Among available environmental power sources, temperature gradients originated at different locations of the aircraft can be used by thermo-electric generators (TEGs) to create electrical voltage. TEGs are lightweight, provide high-energy conversion and do not contain movable parts. Thermal diffusion systems, commonly known as heatsinks, can be combined with TEGs to enhance their performance by increasing heat dissipation from a high temperature surface to the ambient
\end{abstract} air.

This paper focused on the enhancement of TEG performance by developing an air-cooled heatsink for low-power wireless structural health monitoring applications. The design, manufacturing and testing of the proposed thermal diffusion system was investigated by evaluating the increase of the temperature gradient between the opposite surfaces of a commercial TEG element. The thermal performance of the heatsink was assessed with numerical finite element thermal simulations and validated with experimental tests. Experimental results revealed that the proposed thermal diffusion system provided higher temperature differences and, therefore, higher output power in comparison with traditional cylindrical pin-fin heatsinks. A hybrid heat diffusion system composed by copper heatsinks and highly oriented pyrolytic graphite layers was also here proposed in order to allow TEG reaching wireless SHM operative power requirements of tens of $\mathrm{mW}$ and, at the same time, adapt the assembly to the complexity of aerospace SHM arrangements. Experimental results revealed that the proposed heatsink-TEG arrangement was able to generate an output power over $25 \mathrm{~mW}$.

Keywords: power harvesting; thermo-electric generator; heatsink.

\section{Introduction}

In the last years, carbon fibre-reinforced plastic (CFRP) composite materials have been increasingly used in aerospace sector due to their good in-plane mechanical and lightweight properties. However, low velocity impacts can generate barely visible impact damage (BVID), micro-cracks and delamination, which can irreparably affect the integrity of composite structures. In particular, if the impact occurs at very low velocity, damage can be a mixture of splitting between fibres, matrix cracking, fibres fracture and internal delamination due to inter-laminar shear and tension. These damaged modes weaken the structure and can be completely invisible when viewed from the external impacted surface. Hence, automated prognostic and 
structural health monitoring (SHM) systems have become necessary in order to improve maintenance and thus, reduce costs. In order to execute the monitoring of aircraft components, a number of sensing devices are needed at different locations of the aerospace vehicle where sensible data can be captured. The communication among sensors and a central computer (or other sensors) is then necessary to make information available for end-users. On operating aircraft, data is transferred by wires that, unfortunately, provide a large contribution to the overall weight and require expensive maintenance. Thus, in recent times, aircraft companies are interested to sensing networks able to transmit information wirelessly. Since wireless systems require electrical power-on-demand for a variety of sensing applications, micro-power generators can be considered as a valuable alternative to current sources of energy such as batteries and power supplies, as they can extract energy from the surrounding environment. However, whilst power harvesting systems have been widely developed and described in literature for large-scale applications such as wind turbines [1], there is still a lack of technology for small-scale devices such as SHM systems for aerospace [2], [3]. Aircraft structures generally waste a large quantity of energy, mainly originated from natural sources such vibrations and heat, which could be harvested and reused. As an example, electrical current can be obtained from temperature gradients available at different locations of the aircraft (e.g. surrounding the engine), which can be used by thermo-electric generators (TEGs). The harvesting of mechanical vibration energy has also been considered by a number of authors [4], [5], but thermo-electric applications, when available, have showed a higher power output [6] in the range of tens of mW and good reliability [7]. TEGs are suitable for aerospace energy harvesting since they are lightweight, do not contain movable parts and provide high-energy conversion. Thermal diffusion systems (also known as heatsinks) can be used to enhance TEGs performance by increasing heat dissipation from a high temperature surface to the ambient air. The improvement of heatsink cooling performance has been a central problem in the past few years [8], [9] and [10]. The development of integrated circuits, such as central processing units (CPU) for home appliances (e.g. personal computers and graphic processor units), has led to an increase of heat generation so that high-performance heatsinks are needed [11]. Only recently, however, these studies have been applied to thermo-electric energy harvesting [12], [13], and the use of TEGs for powering a wireless SHM system can be still considered an early stage concept [14]. In order to simplify design and optimisation of a TEG-heatsink assembly, computational fluid dynamics (CFD) can be a powerful tool that is able of comparing several heat exchangers under the same boundary conditions [15]. So far, a number of CFD models have been proposed in order to consider the fluid-structure interaction between the examined device and the surrounding environment [16]. Most of these numerical simulations were focused on applications where forced convection is the main heat exchange mechanism [17]. However, in many aerospace applications, such as inside aircraft pylons, the air can be assumed steady so that there is a natural convection regime. This paper is focused on TEG performance improvement through a heatsink in order to make it able to feed a low-power wireless SHM system for aerospace applications. Firstly, a novel heatsink is designed and 
its performance is compared with a classic pin-fin heatsink through CFD analyses, by evaluating both temperature and power output of the TEG upon which they are applied. Then, CFD results are validated through a number of experiments and, finally, two novel heat diffusion systems are combined in a new assembly composed by copper heatsinks and highly oriented pyrolytic graphite layers in order to allow the TEG to reach operative power requirements. The paper is outlined as follows: in Section 2 thermo-electric generators (TEG) are presented. In Section 3 an optimisation process is performed in order to design a novel heatsink, whilst in section 4 the proposed heatsink cooling performance is compared to a classic configuration through computational fluid dynamics (CFD) simulations. Section 5 reports the experimental validation results and Section 6 introduces a TEG-heatsink assembly for SHM. The conclusions of this paper are discussed in Section 7.

\section{Thermo-electric energy harvesting}

The thermo-electric phenomenon is described by two main effects: the Peltier effect and the Seebeck effect. The Peltier effect is the heat generation caused by an electric current flow in the junction of two different conductors [18]. The Seebeck effect, opposite to the Peltier effect, is the electric current generation from a thermal gradient source [19]. The potential difference $V$, due to Seebeck effect, can be expressed as:

$$
\begin{aligned}
& V=\alpha \Delta T \\
& \alpha=\frac{\partial V}{\partial T}
\end{aligned}
$$

where $\Delta T$ is the temperature gradient and $\alpha$ is the Seebeck coefficient, i.e. the variation of potential difference $V$ due to a variation of temperature $T$. Thermo-electric generators (TEG), also known as Peltier elements, are used to harvest energy through the Seebeck effect. A TEG is composed by a number of thermoelectric couples of n-type and p-type semiconductors [20] placed electrically in series and thermally in parallel (figure 1) so that the aggregation of electrons and holes on the cold side (in the n- and p-type legs, respectively) and their diffusion on the hot side create an electrical current able to feed a resistance load. Considering both Ohm's law and Kirchhoff law applied to a circuit having a TEG as the voltage generator, the load potential difference $V_{\text {load }}$ and the electrical current $i$ can be expressed as:

$$
\begin{aligned}
& V_{\text {load }}=R_{\text {load }} i \\
& i=\frac{V}{R_{\text {load }}+R_{\text {int }}}
\end{aligned}
$$

where $R_{\text {int }}$ is TEG internal resistance and $R_{\text {load }}$ is the load resistance. Substituting eq. (3) into eq. (2) leads to:

$$
V_{\text {load }}=\frac{R_{\text {load }}}{R_{\text {load }}+R_{\text {int }}} V_{\text {. }}
$$

The TEG power output that feeds the load, $P_{\text {load }}$, can be defined as: 


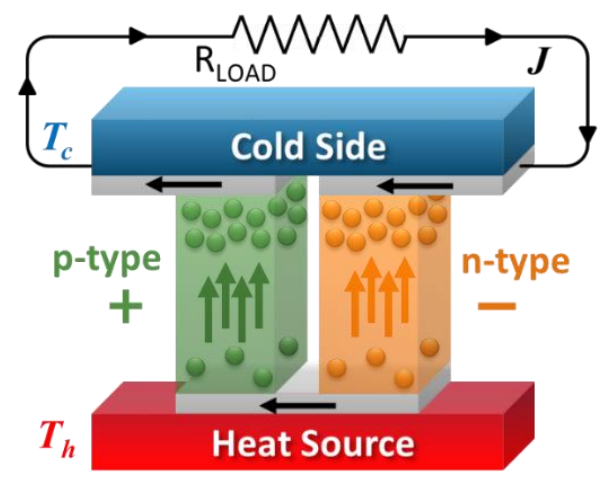

Figure 1. Peltier element: the particles (holes and electrons) tend to accumulate on the cold side creating a potential difference.

$$
P_{\text {load }}=\frac{V_{\text {load }}^{2}}{R_{\text {load }}}
$$

and, thus, considering eqs. (4) and (1), it can be written as:

$$
P_{\text {load }}=\frac{R_{\text {load }}}{\left(R_{\text {load }}+R_{\text {int }}\right)^{2}} V^{2}=\frac{R_{\text {load }}}{\left(R_{\text {load }}+R_{\text {int }}\right)^{2}}(\alpha \Delta T)^{2}
$$

Once the TEG is chosen, the internal resistance $R_{\text {int }}$, the load resistance $R_{\text {load }}$ and the Seebeck coefficient $\alpha$ are known properties so that the output power $P_{\text {load }}$ only depends on the temperature difference $\Delta T$, and can be calculated by using eq. (6). Figure 2 shows a curve representing TEG power output in function of load resistance at a fixed (constant) temperature difference $\Delta T$ of $24^{\circ} \mathrm{C}$. The maximum power output is obtained when $R_{\text {load }}=R_{\text {int }}$ (i.e. $1.5 \Omega$ as in the case of figure 2 ) so that:

$$
P_{\max }=\frac{V^{2}}{4 R_{\text {int }}}=\frac{(\alpha \Delta T)^{2}}{4 R_{\text {int }}}
$$

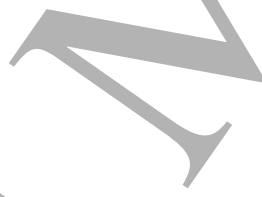

\section{Natural convection air cooling heatsinks}

Since the internal resistance and Seebeck coefficient are material (constant) properties of the TEG element, with reference to Eqs. (6) and (7), the TEG power output can be increased by enhancing the temperature difference between its top and bottom faces. Since the hot face temperature of the Peltier element depends on the available heat source, that is generally fixed and cannot be controlled, the temperature difference can be increased only by decreasing the temperature of TEG cold face. Many thermal cooling methods have been developed in the past years [12]. In an aerospace environment, volume and weight must be kept as small as possible and, thus, several cooling strategies, including the use of liquid cooling systems have to be discarded. Hence, a suitable option for aerospace applications is air cooling through a heatsink placed on the cold face of the TEG. Considering an adiabatic indoor environment such as inside an aircraft pylon, the air can be assumed steady, so that natural convection is the main mechanism of heat transfer [21].

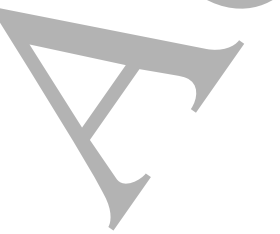


Table 1. Considered pin shapes, requirements and manufacturing limitations.

\section{Circular pin \\ Rectangular pin}

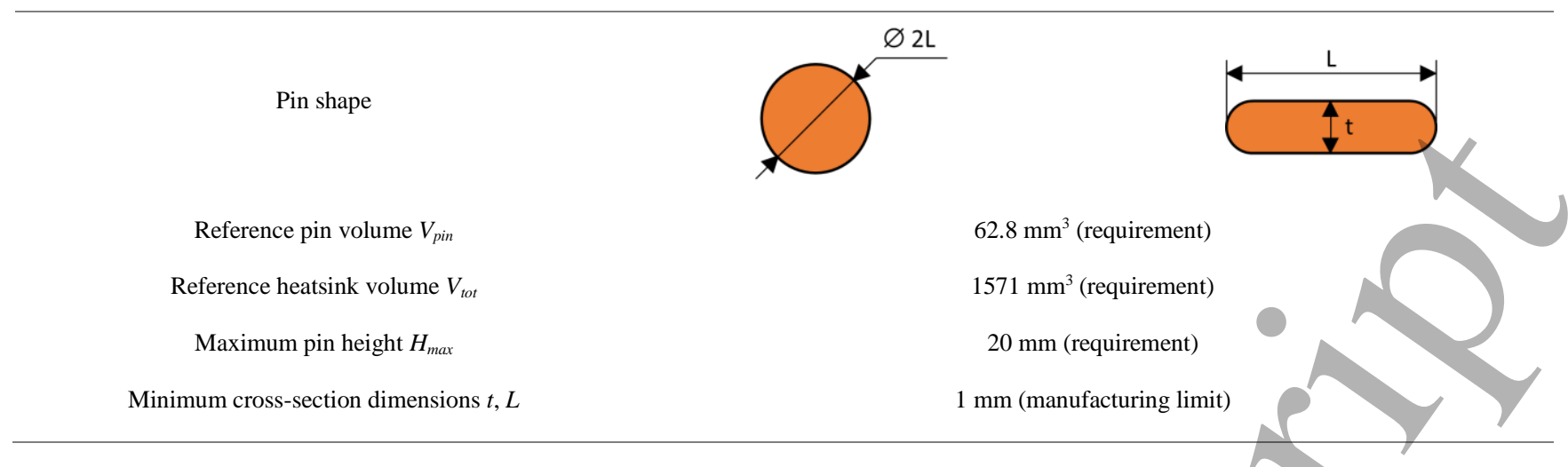

Since the heat transfer is a combination of conduction and convection (radiation can be neglected), the heatsink performance can be improved by choosing the right material and appropriate geometry. Thermal conduction can be improved by using a high thermal conductivity material. Copper and aluminium are the most common heatsink materials for aerospace application due to their ductility, good thermal properties and relatively cheap price. However, copper shows a thermal conductivity higher than aluminium $(400 \mathrm{~W} /(\mathrm{mK})$ and $220 \mathrm{~W} /(\mathrm{mK})$, respectively) and, thus, considering a constant volume, it has a better performance in terms of conductive heat transfer. Convective thermal exchange, according to Newton's cooling law, can be enhanced by (a) increasing the temperature gradient between heatsink and ambient, (b) increasing the convection heat transfer coefficient and (c) increasing the surface area of the heatsink. The latter is the most achievable and cost-effective option. Hence, the focus of the proposed research was the design of a new heatsink geometry capable of enhancing the TEG cooling performance [22].

\subsection{Pin-fin heatsink optimisation}

The most common heatsink configuration consists of a flat base with surface-mounted pins, so that the geometry of each pin can be modified to increase the heat transfer rate. In this work, a classic cylindrical pin heatsink (Figure 4a) was here set as a reference and, taking into account manufacturing limitations, a novel heatsink was created by keeping same weight and height (Figure $4 \mathrm{~b}$ and Table 1). In the interest of maintaining the manufacturing process as simple as possible, two basic pin cross-sections, circular and rectangular, were chosen and analysed in order to maximise the pin external surface (Table 1). An analytical optimisation process was carried out for both pin shapes so that an ideal characteristic dimension $L$ (i.e. either the radius of the circular pin section or the length of the rectangular pin section) could be calculated. The expressions for the pin height $H$ were deduced from the pin volume $V_{\text {pin }}$ formulae: 


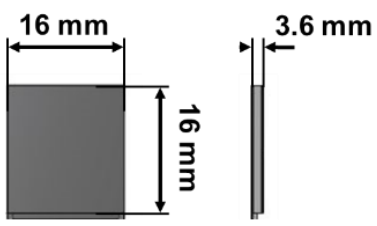

Figure 3. Illustration of TEG geometry.

Circular pin section

$$
\begin{aligned}
& V_{\text {pin }}=\pi L^{2} H \\
& H=\frac{V_{\text {pin }}}{\pi L^{2}}
\end{aligned}
$$
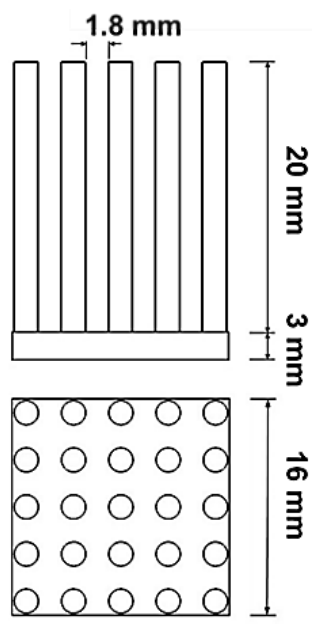

(a)

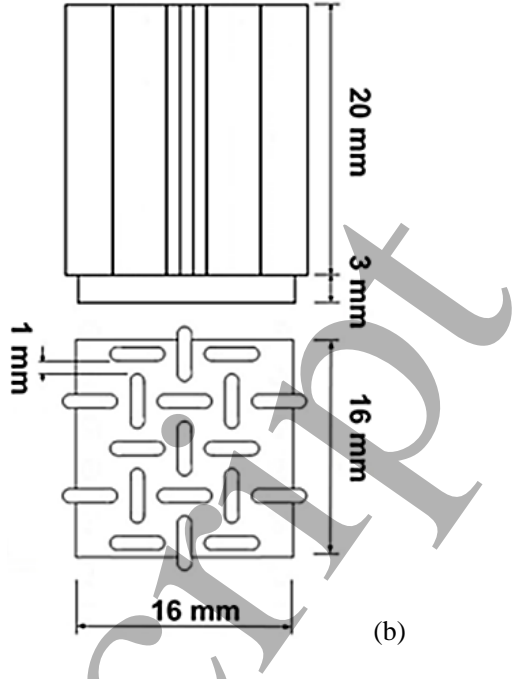

Figure 4. Heatsink geometries with (a) classic cylindric pin and (b) novel pin arrangements.

\section{Rectangular pin section}

$$
\begin{aligned}
& V_{\text {pin }}=t H L \\
& H=\frac{V_{\text {pin }}}{t L}
\end{aligned}
$$

where $t$ is the minimum thickness of the rectangular shape. Since, in the case of pins, most of the total surface area is given by the lateral surface area, the expressions for the pin external surface $S_{\text {pin }}$ can be simplified as:

$$
S_{\text {pin }}=2 \pi L H \quad S_{\text {pin }}=2(L+t) H
$$

Substituting Eqs. (8b) in Eqs. (9) yields:

$$
S_{\text {pin }}=\frac{2 V_{\text {pin }}}{L} \quad S_{\text {pin }}=2 V_{\text {pin }}\left(\frac{1}{t}+\frac{1}{L}\right)
$$

The characteristic dimension was varied between $1 \mathrm{~mm}$ (manufacturing limit) and $10 \mathrm{~mm}$ and the results are showed in Figure 5. According to the requirements and the manufacturing limits, the optimal characteristic dimensions were $1 \mathrm{~mm}$ and $3.2 \mathrm{~mm}$ for circular and rectangular pin sections, respectively. The rectangular pin showed a higher external surface and, thus, it was chosen as a pin shape for the novel heatsink. As reported in Figure 5b, the rectangular pin optimal length $L$ was 3.2 mm. However, such a length value can be considered as an ideal case that requires high tolerance and can be realised, for instance, through additive manufacturing technology. In this research work, computer numerical control (CNC) machining was the available manufacturing process so that the characteristic dimension had to be increased to $L=4 \mathrm{~mm}$. Hence, a new study was necessary to find the number of novel pins $N_{\text {pin }}$ that matches the total volume of the reference heatsink (Figure 6). The expression of the total volume $V_{\text {tot }}$ allows to calculate the characteristic dimension $L$ in function of the number of pins $N_{\text {pin }}$ : 


\section{1}

2

3

4

5

6

7

8

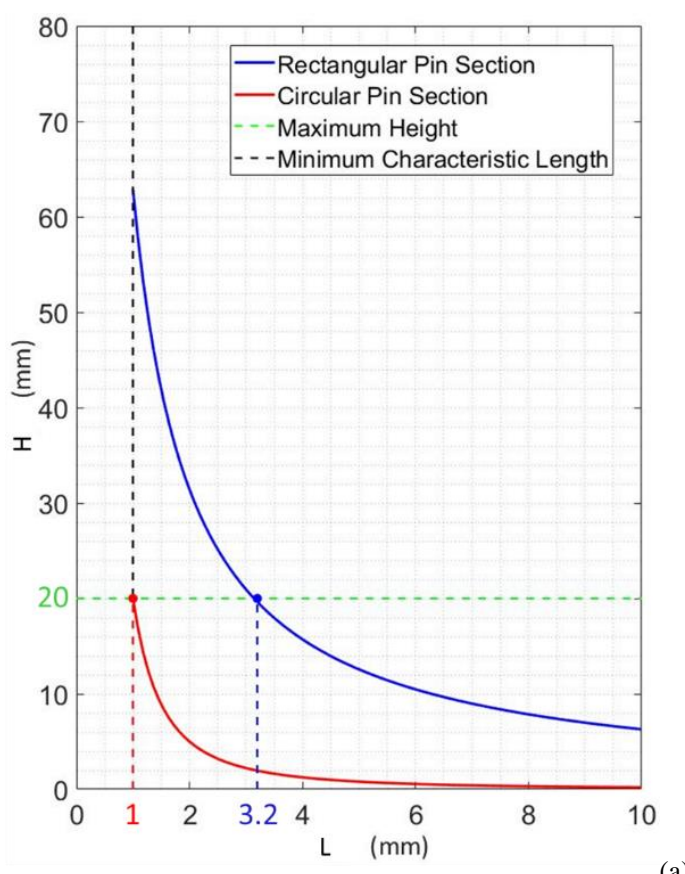

(a)

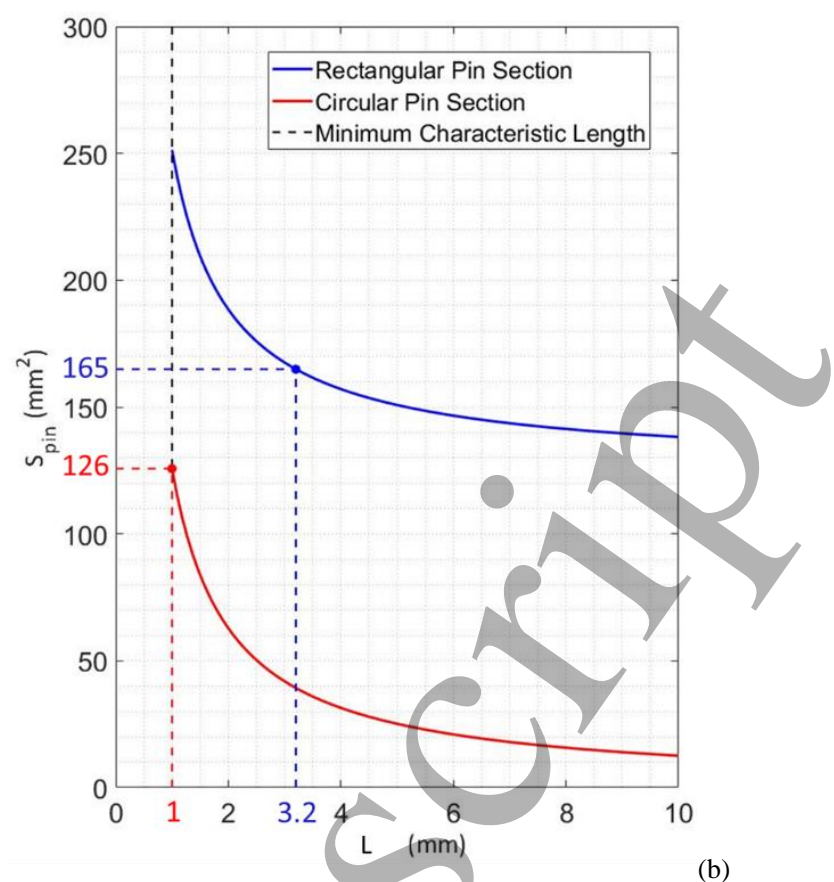

(b)

Figure 5. Optimisation of the pin shape: (a) pin height and (b) pin external surface area in function of the characteristic dimension.

\section{Circular pin section}

$$
\begin{aligned}
& V_{\text {tot }}=N_{\text {pin }} \pi L^{2} H_{\text {max }} \\
& L=\sqrt{\frac{V_{t o t}}{N_{\text {pin }} \pi H_{\max }}}
\end{aligned}
$$

\section{Rectangular pin section}

$$
\begin{aligned}
& V_{t o t}=N_{\text {pin }} t H_{\text {max }} L \\
& L=\frac{V_{\text {tot }}}{N_{\text {pin }} t H_{\max }}
\end{aligned}
$$

where $H_{\max }$ is the maximum height from reference $(20 \mathrm{~mm})$.
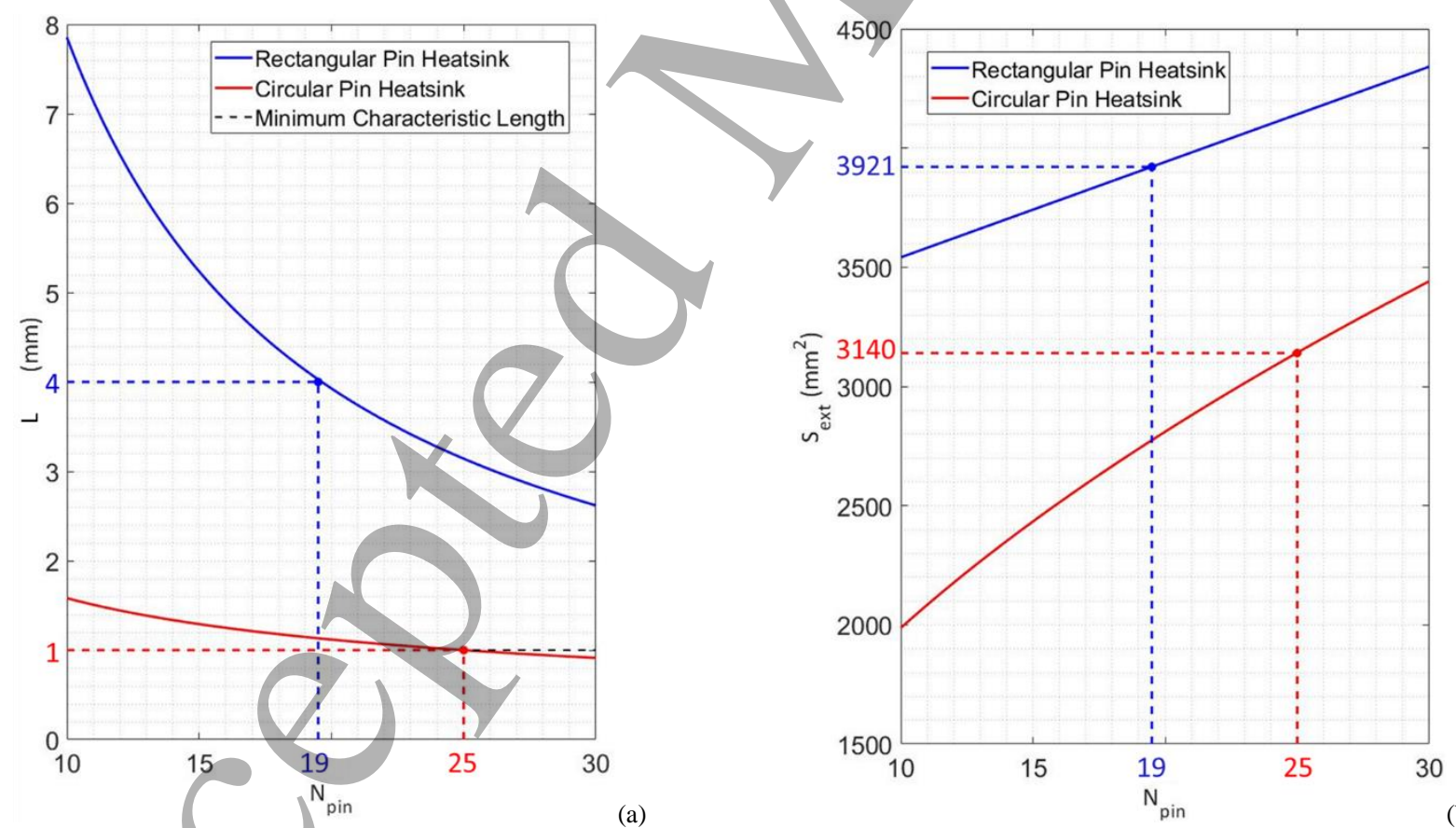

Figure 6. Optimisation of the pin number: (a) pin characteristic dimension and (b) pin external surface area in function of the pin number. 
Table 2. Material properties.

\begin{tabular}{|c|c|c|c|c|c|}
\hline \multicolumn{2}{|c|}{ Thermoelectric Generator (TEG) } & \multicolumn{2}{|c|}{ Heatsink (HS) - Copper } & \multicolumn{2}{|c|}{ Pyrolytic Graphite Sheet (PGS) } \\
\hline Density & $5.4 \mathrm{~g} / \mathrm{cm}^{3}$ & Density & $8.92 \mathrm{~g} / \mathrm{cm}^{3}$ & Density & $2.1 \mathrm{~g} / \mathrm{cm}^{3}$ \\
\hline Weight & $5 \mathrm{~g}$ & Weight & $20 \mathrm{~g}$ & Weight & $<0.1 \mathrm{~g}$ \\
\hline Thermal conductivity & $0.08 \mathrm{~W} /(\mathrm{mK})$ & Thermal conductivity & $400 \mathrm{~W} /(\mathrm{mK})$ & Thermal conductivity & $1950 \mathrm{~W} /(\mathrm{mK})$ \\
\hline Internal resistance & $1.5 \mathrm{Ohm}$ & Specific heat & $385 \mathrm{~J} /(\mathrm{kgK})$ & Thickness & $25 \mu \mathrm{m}$ \\
\hline Seebeck coefficient & $0.012 \mathrm{~V} / \mathrm{K}$ & & & & \\
\hline
\end{tabular}

The expressions for the heatsink external surface $S_{e x t}$ can be written as:

$$
S_{\text {ext }}=2 N_{\text {pin }} \pi L H_{\text {max }} \quad S_{\text {ext }}=2 N_{\text {pin }}(L+t) H_{\text {max }}
$$

Substituting Eqs. (11b) in Eqs. (12) yields:

$$
S_{\text {ext }}=2 \sqrt{N_{\text {pin }} \pi H_{\text {max }} V_{\text {tot }}} \quad S_{\text {ext }}=\frac{2 V_{\text {tot }}}{t}+2 N_{\text {pin }} H_{\text {max }} t .
$$

\section{Thermal CFD analysis in a natural convection environment}

\subsection{Numerical CFD simulation set-up}

ANSYS Fluent was used to perform a number of 3D CFD simulations so that fluid-structure interactions could be numerically analysed. The whole assembly was set inside a box with dimensions $300 \mathrm{~mm}$ x $300 \mathrm{~mm} \times 300 \mathrm{~mm}$ in order to neglect boundary effects. According to section 3, natural convection was considered as solid-fluid thermal exchange mechanism and, since the TEG-heatsink assembly was set inside a closed domain, a steady-state calculation was possible by using the Boussinesq model [23][23]. In this model, density can be assumed as a constant in balance equations. The only exception is the density in the buoyancy term of the momentum equation, which can be approximated as follows:

$$
\left(\rho-\rho_{0}\right) g \approx-\rho_{0} \beta\left(T-T_{0}\right)
$$

where $\rho_{0}$ is the constant density of the flow, $T_{0}$ is the operating temperature, $g$ is the gravity acceleration, and $\beta$ is the thermal expansion coefficient. Eq. (14) is obtained by using the Boussinesq approximation:

$$
\rho=\rho_{0}(1-\beta \Delta T)
$$

in order to eliminate $\rho$ from the buoyancy term. This approximation is allowed in the present case since $\beta\left(\mathrm{T}-\mathrm{T}_{0}\right) \ll 1$. Thermal models were built with ANSYS Mechanical APDL software, whilst ANSYS Workbench allowed meshing the thermal system composed by the TEG and the heatsink (figure 8 and table 3). Once boundary conditions were applied, the thermal solution was calculated using ANSYS Fluent. A fixed temperature of $100^{\circ} \mathrm{C}$ was applied to the TEG hot side and the ambient temperature was set at $25^{\circ} \mathrm{C}$ (figure 7).

Table 3. Summary of finite element models. 


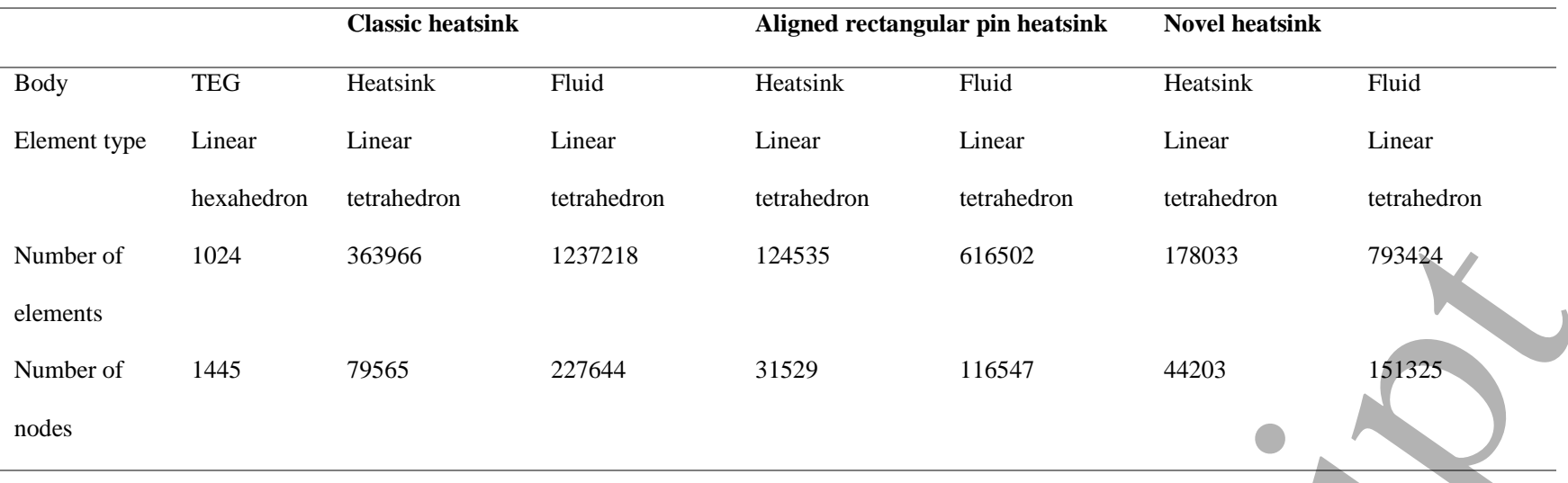

A layer of insulant material was inserted between the TEG and the heatsink in order to take into account the air-filled regions due to the roughness at TEG-heatsink interface. MATLAB software was used to post-process temperature differences achieved in the numerical FE simulations in order to obtain TEG power outputs.

\subsection{Pin disposition choice and heatsink comparison via CFD}

Once the shape and the number of pins have been chosen, thermal CFD simulations were performed in order to compare two novel pin dispositions and choose the best pin arrangement in terms of cooling effect on the TEG. Moreover, the cooling effect of the examined heatsinks was compared to a classic cylindrical pin heatsink. In a natural convection environment, considering an input temperature of $100^{\circ} \mathrm{C}$ on TEG lower face and $25^{\circ} \mathrm{C}$ as ambient temperature, the aligned rectangular pin heatsink allowed a TEG temperature difference $\Delta T$ of $22^{\circ} \mathrm{C}$ whilst the rectangular pin mixed disposition increased such a value to $22.7^{\circ} \mathrm{C}$.

\section{Box full of air at}

$25^{\circ} \mathrm{C}$

Heatsink

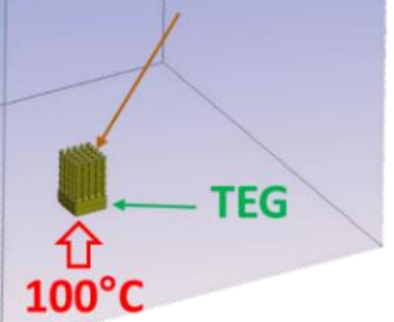

Figure 7. CFD simulation set-up. 


\section{1}

2

3

4

5

6

7

8

9

10

11
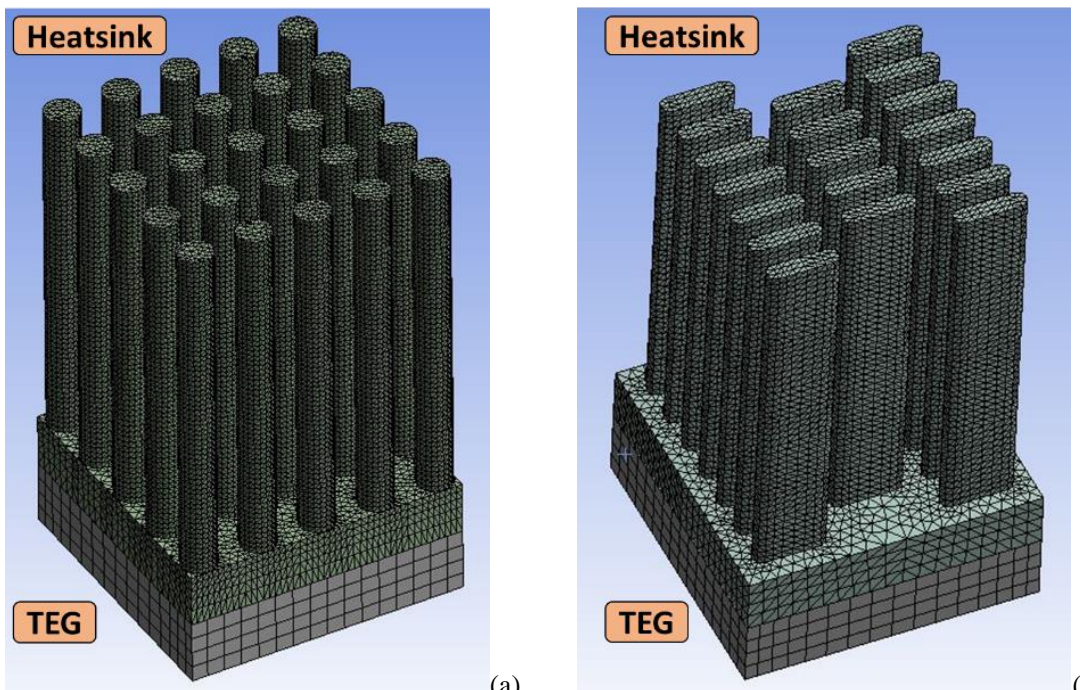

(a)

(b)

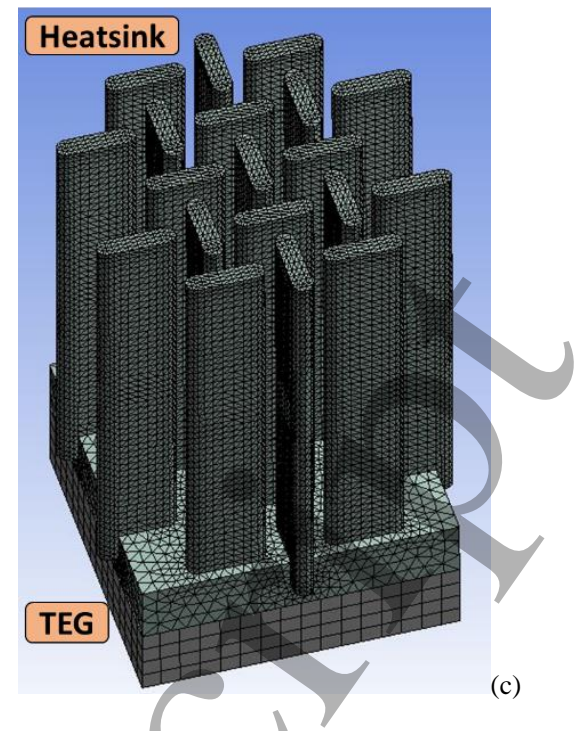

Figure 8. Meshed geometry of the TEG together with (a) classic, (b) aligned rectangular pin and (c) novel heatsinks.

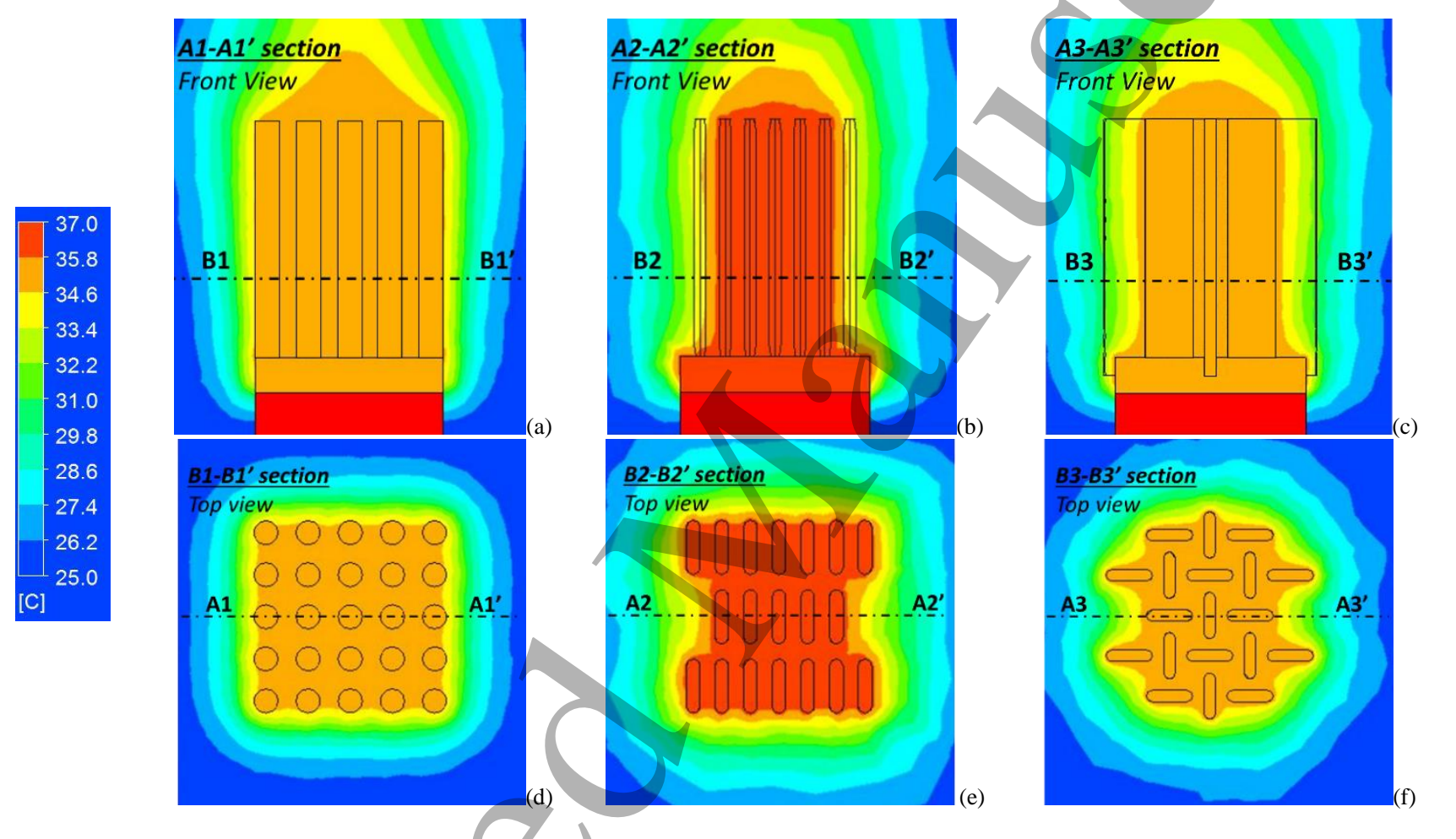

Figure 9. CFD simulation results: static temperature contour of classic (a)-(d), aligned rectangular pin (b)-(e) and novel (c)-(f) heatsink. Sections B-B' are placed at a height of $10 \mathrm{~mm}$ from the bottom of the TEG whilst sections A-A' placed right in the middle of the TEG-heatsink system.

The TEG temperature difference due to the cylindrical pin heatsink resulted to be the lowest $\left(\Delta T=18.7^{\circ} \mathrm{C}\right)$. Such an increase of thermal difference is due to the enhanced thermal exchange surface of new pin geometry (Figures $8 \mathrm{a}, 8 \mathrm{~b}$ and $8 \mathrm{c}$ ) and the reduced size of the hot air region by means of the new pin arrangement (Figures $8 \mathrm{~d}, 8 \mathrm{e}$ and $8 \mathrm{f}$ ). Thus, the heatsink with rectangular pin mixed disposition can be considered as the novel heatsink. The temperature drop between TEG and heatsink is caused by the presence of an insulant layer representing poor thermal coupling. Further, according to section 2 , numerical temperature differences were used as input in Eq. (6) to obtain power outputs at different load resistances. 


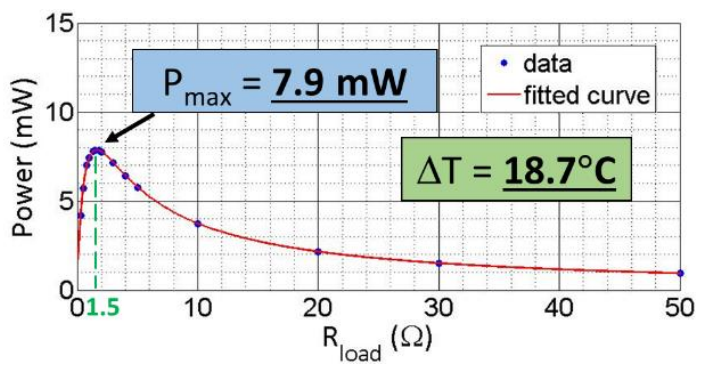

(a)
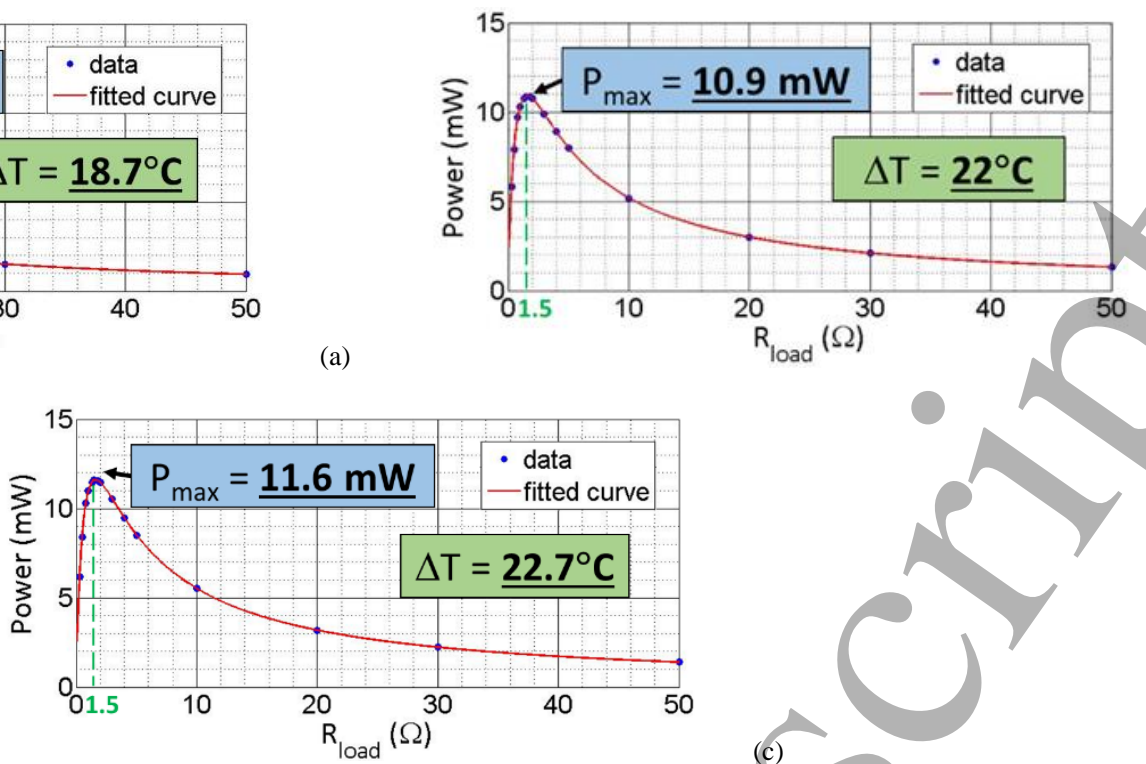

Figure 10. Numerical TEG power output by using (a) classic, (b) aligned rectangular pin and (c) novel heatsinks. The temperature differences $\Delta T$ are calculated by averaging node temperatures on bottom (hot) and top (cold) areas of the TEG.

The maximum TEG power outputs were $7.9 \mathrm{~mW}, 10.9 \mathrm{~mW}$ and $11.6 \mathrm{~mW}$ by using cylindrical pin heatsink, aligned rectangular pin heatsink and novel heatsink, respectively (Figure 10).

\section{Experimental validation of CFD results}

\subsection{Specifications and material properties}

The two different heatsink geometries, introduced in section 3, were manufactured by following the same procedure, i.e. fixing a number of pins on a flat base (table 2 and figures 3 and 4, respectively). Thus, simulation results were validated through a number of experiments. Looking at figure 11, the heat source was reproduced through a Heidolph MR Hei-Standard hot plate and load conditions were introduced by using a Cambridge Instrument ACDC decade resistor. The room temperature was set at $25^{\circ} \mathrm{C}$ and two thermocouples, placed on both the hot and the cold side of the TEG, allowed an experimental temperature difference evaluation. A PicoScope PC Oscilloscope was linked to a computer to capture the TEG output voltage and MATLAB was used to analyse the results. The output voltages $(V)$ were captured at different load resistances $\left(R_{\text {load }}\right)$ ranging between $0 \Omega$ and $50 \Omega$, and the resulting power outputs were calculated through eq. (5). A Fischer Elektronic siliconfree thermally conductive paste (WLPK-10) was used to improve the thermal coupling between TEG and heatsink.

\subsection{Experimental TEG temperature difference and power output}

Several experiments were carried out to validate the numerical CFD results in section 4, which are shown in figures 9 and 10. As in the numerical model, the hot plate and room temperatures were set at $100^{\circ} \mathrm{C}$ and $25^{\circ} \mathrm{C}$, respectively 


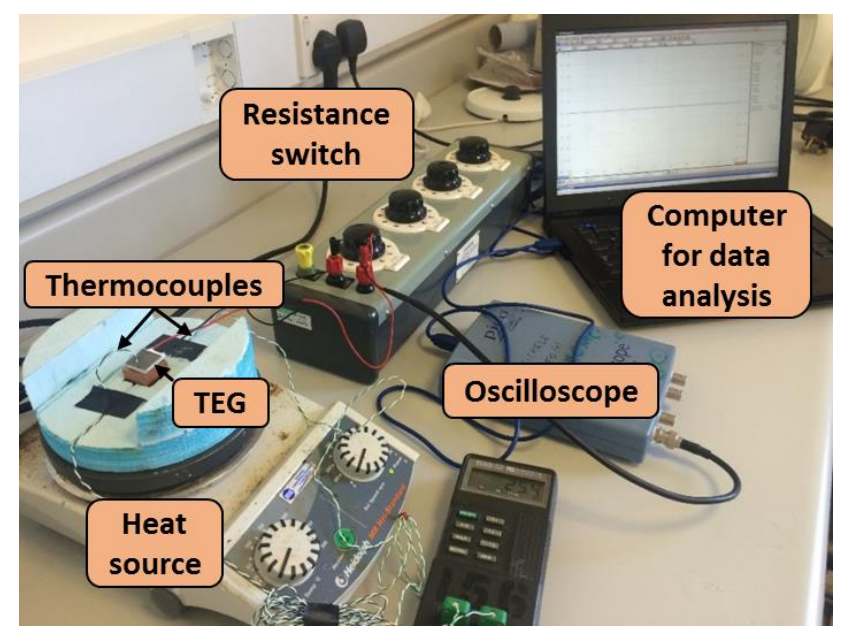

Figure 11. Experimental set-up.

Experimental tests showed that the introduction of the novel heatsink improved TEG natural convection cooling since it led to a measured temperature difference $\Delta T$ of $20^{\circ} \mathrm{C}$, nearly $2.3^{\circ} \mathrm{C}$ higher than cylindrical pin heatsink configuration. The measured TEG power output data was fitted using eq. (6) (figure 12) so that maximum power output was $7.3 \mathrm{~mW}$ and 8.9 $\mathrm{mW}$ using classic and novel heatsink, respectively. It should be noted that experimental temperature differences resulted to be slightly lower than the numerical results. This could be due to temperature losses caused by manufacturing defects including stuck/stacked fin poor thermal contact and material impurities. These losses were not simulated in the numerical CFD model.
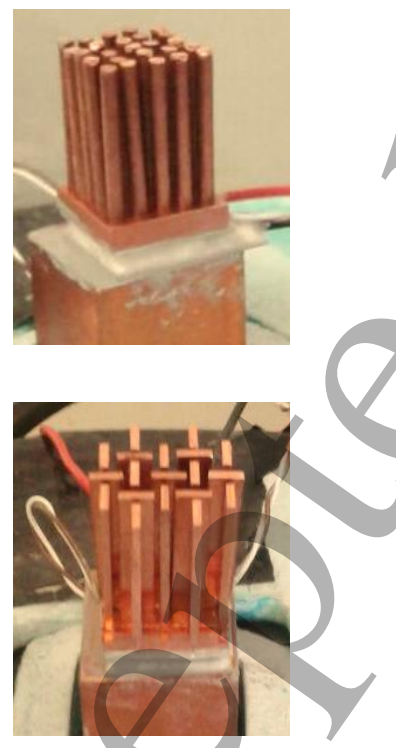

Figure 12. TEG power output comparison: (a) the classic cylindric pin shape heatsink and (b) the proposed novel pin shape heatsink. (a)

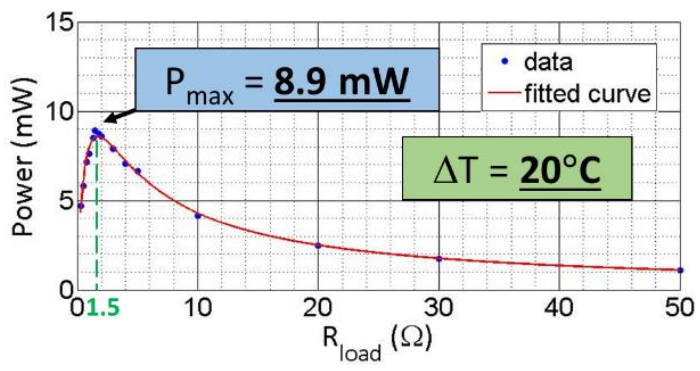

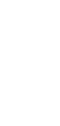


Table 4. TEG temperature differences and power output at different input temperatures.

4

6

10

11

\begin{tabular}{|c|c|c|c|c|}
\hline \multirow{2}{*}{$\begin{array}{c}\text { TEG hot temperature } \\
\qquad \mathbf{T}_{\text {hot }}\left({ }^{\circ} \mathbf{C}\right)\end{array}$} & \multicolumn{2}{|c|}{ Temperature difference $\Delta \mathrm{T}\left({ }^{\circ} \mathrm{C}\right)$} & \multicolumn{2}{|c|}{ Maximum power output $P_{\max }(\mathrm{mW})$} \\
\hline & Classic heatsink & Novel heatsink & Classic heatsink & Novel heatsink \\
\hline 50 & 4.3 & 4.8 & 0.6 & 0.8 \\
\hline 75 & 11.5 & 13.3 & 3.1 & 4.2 \\
\hline 100 & 17.7 & 20.1 & 7.3 & 8.9 \\
\hline 125 & 24 & 26.2 & 12 & 14.1 \\
\hline 150 & 31.7 & 34 & 20.2 & \\
\hline
\end{tabular}

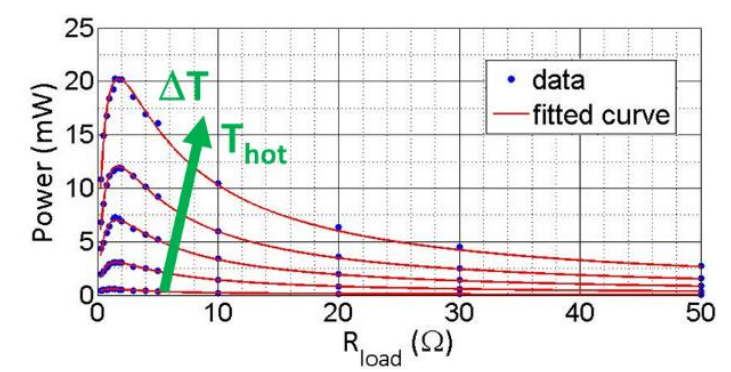

(a)

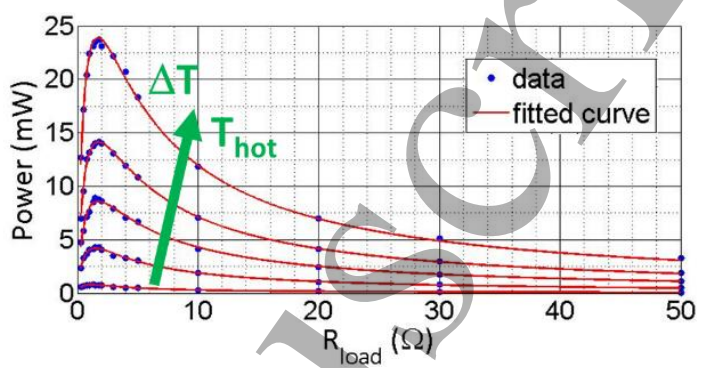

(b)

Figure 13. TEG power output curve behaviour at different hot temperatures: (a) classic heatsink case and (b) novel heatsink case. In both cases, the power output (red curves) increases with the input temperature $\left(50^{\circ} \mathrm{C}, 75^{\circ} \mathrm{C}, 100^{\circ} \mathrm{C}, 125^{\circ} \mathrm{C}\right.$ and $150^{\circ} \mathrm{C}$, from bottom to top)."
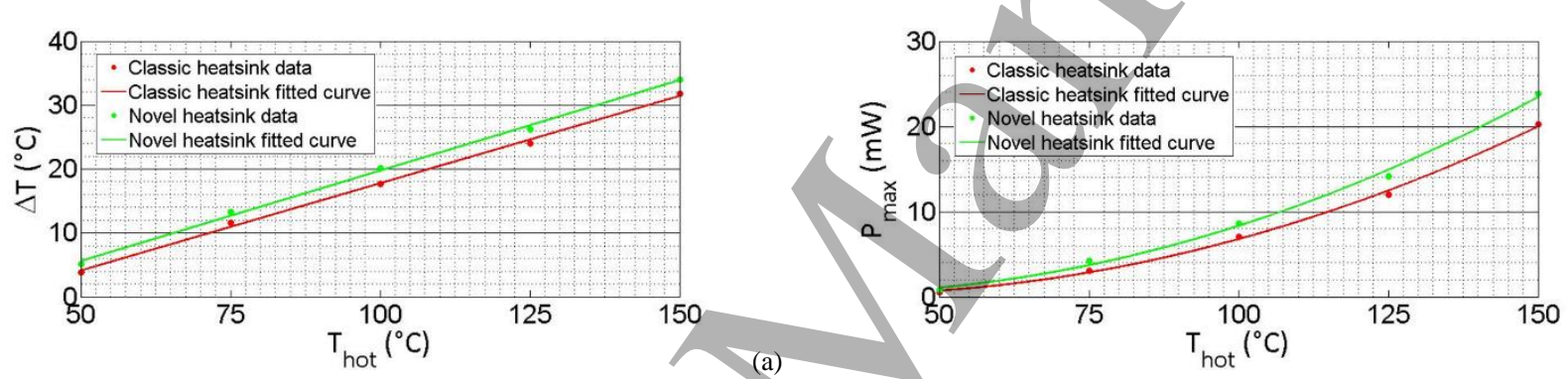

Figure 14. Heatsink effect comparison at different input temperatures: (a) TEG temperature difference and (b) TEG power output.

\subsection{Experiments at different TEG hot side temperatures}

A number of experiments was carried out in order to understand how the hot plate temperature affected the TEG temperature difference and, in turn, the TEG power output. The hot plate was set at a constant temperature between $50^{\circ} \mathrm{C}$ and $150^{\circ} \mathrm{C}$ (see table 4) and both the classic and novel heatsinks were bonded on a single TEG as in section 5.2.Thermal results confirmed, once more, the higher cooling effect of the novel heatsink applied on the TEG cold face. With reference to figures 13 and 14 , the increase of hot temperature led to a linear increase of temperature difference and a quadratic increase of maximum power output (in accordance with section 2). 

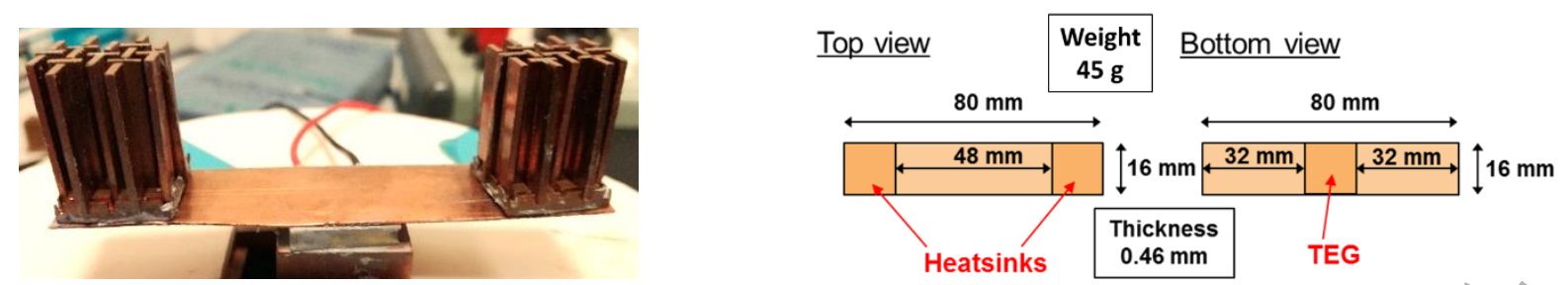

\section{TEG-heatsink assembly for wireless SHM applications}

\subsection{Introduction}

In order to power a wireless SHM system, there is the necessity to further increase TEG power output (typically in the range of few $\mathrm{mW}$ ) up to two/three times more [24]. Thus, a system including more than one heatsink can be a valid solution to enhance TEG temperature difference. However, in most of aerospace applications, the space available for heatsinks can be limited, or even not sufficient, due to the complexity of some SHM arrangements. This issue can be overcome by transferring the heat from the TEG to a location where heatsinks can be placed. A high thermal conductivity material can be used to link TEG and heatsinks so that the heat can quickly spread and dissipate. Based on these considerations, the heatsink assembly proposed in this work consists of two novel heatsinks placed on a copper sheet (figure 15). By assuming that a quick heat transfer corresponds to a higher cooling performance, the heatsink system was improved by placing pyrolytic graphite sheets (PGS) on the copper plate. PGS have a very high in-plane thermal conductivity $(1950 \mathrm{~W} / \mathrm{mK}$, see table 2$)$ so that they can be used to enhance the heat spreading and, accordingly, the dissipation. By using the heatsink system composed by a combination of copper and PGS materials, the TEG power output could be sufficient to power a wireless SHM system.

\subsection{Experimental results}

The improvement of the TEG performance due to the novel heatsink led to the possibility of feeding a low-power electronic system, such as a wireless structural health monitoring (SHM) device. In order to reach the power requirements of tens of $\mathrm{mW}$ [24], a heatsink assembly was created by combining two new heatsinks through a copper sheet and then placed on the TEG top side (figure 15). Since heat diffuses from TEG to the heatsinks, the cooling performance of the assembly was improved by adding a layer of super-conductive material to the copper sheet in order to allow a faster heat transfer. Pyrolytic graphite sheets (PGS, table 2) were chosen to fulfil this task because of their very high in-plane thermal conductivity. According to previous sections, a number of experiments was carried out and both TEG temperatures and power outputs were measured. The TEG temperature difference achieved with two heatsinks placed on a copper sheet was $29.3^{\circ} \mathrm{C}$ and the maximum power output of the device was $20.1 \mathrm{~mW}$ (figure 16a). PGS application increased the heat transfer and, accordingly, the power output. The PGS layer was firstly applied on the top face of the copper sheet (below the heatsinks, figure 16b).

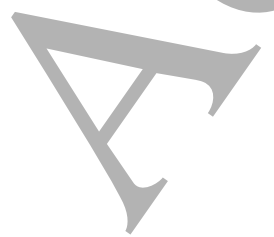



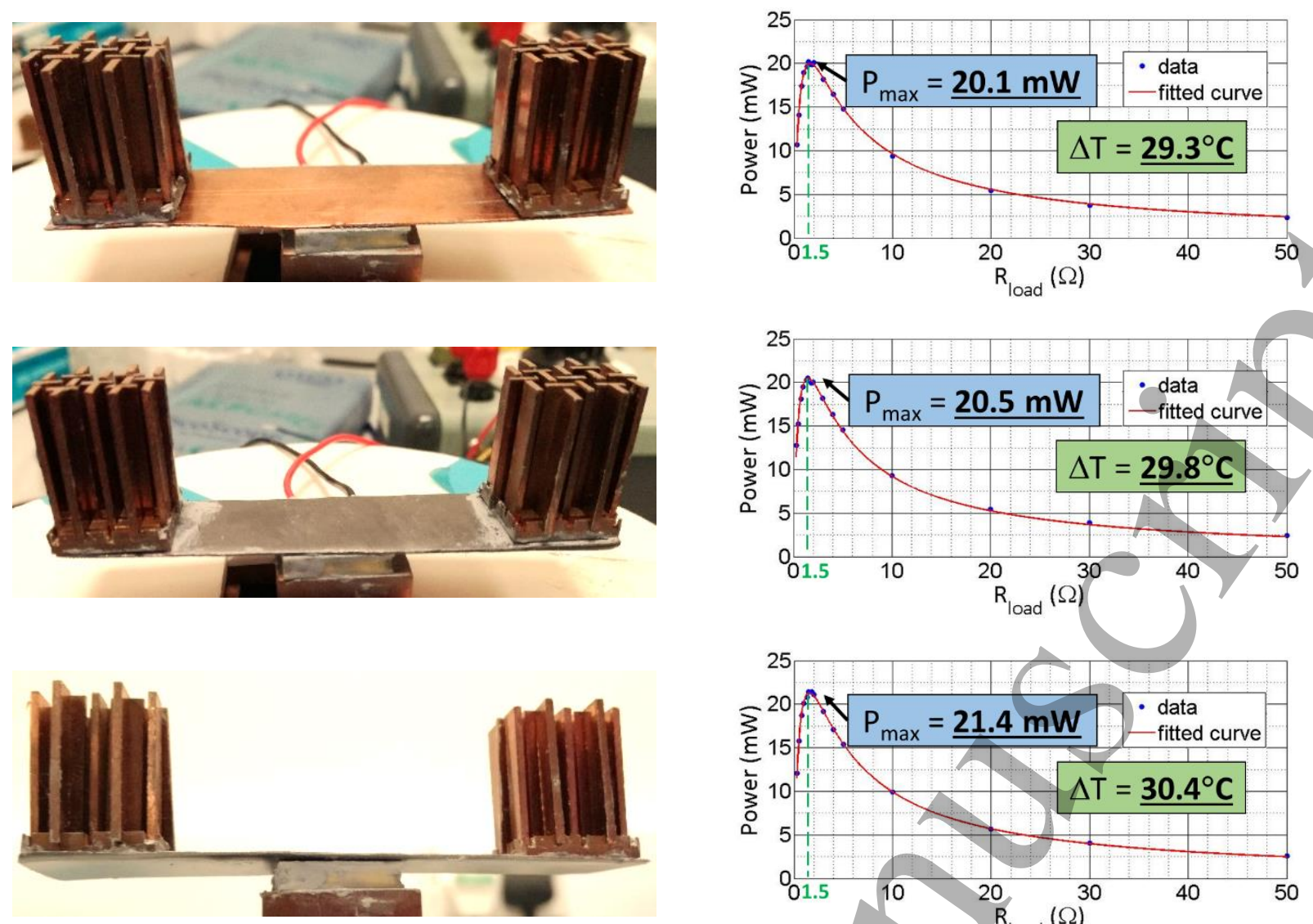

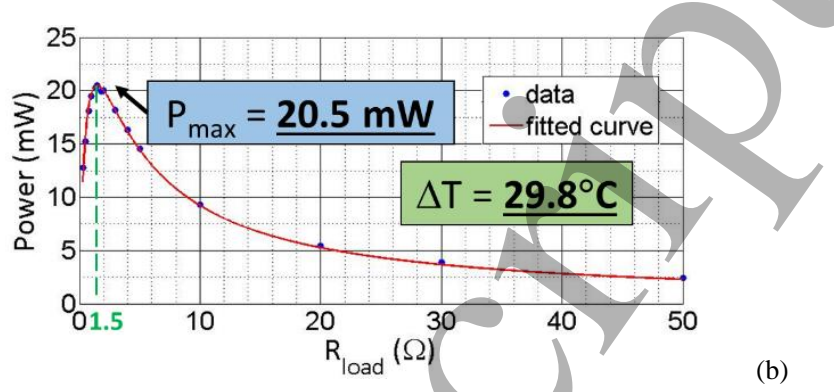

(b)

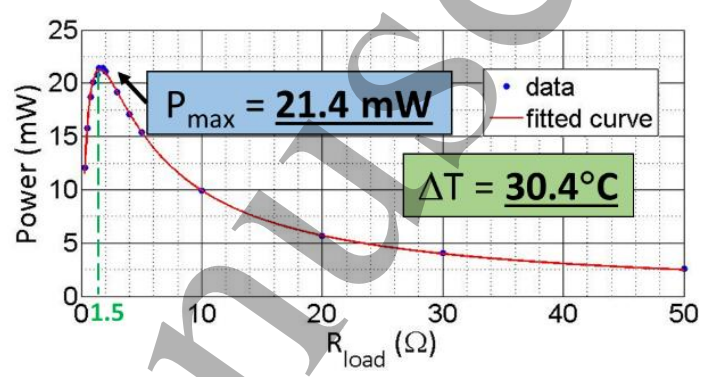

(c)

Figure 16. TEG-heatsink assembly experimental set-up and results (a) without PGS, (b) with PGS on top of the copper sheet and (c) with PGS on bottom of the copper sheet.

TEG temperature difference increased to $29.8^{\circ} \mathrm{C}$ and, thus, the maximum power output increased to $20.5 \mathrm{~mW}$. Then, PGS was applied on the bottom face of the copper sheet (figure 16c) and, once again, both TEG temperature difference and maximum power output increased to $30.4^{\circ} \mathrm{C}$ and $21.4 \mathrm{~mW}$, respectively. This configuration gave the best results because PGS high in-plane thermal conductivity was more effective when the graphite was directly in contact with the TEG. The generated energy can be maximised by using an impedance matching circuitry between TEG $\left(R_{\text {int }}=1.5 \Omega\right)$ and load [25]. The power output of the proposed device can be considered enough to feed a wireless SHM system suitable for aerospace structures $(0.15$ $\mathrm{mW}$ in inactive mode, $18 \mathrm{~mW}$ during transmission [24]). Although the two-heatsink arrangement allowed the harvesting of a good amount of power, it is much heavier than the system involving only one heatsink (45 grams instead of 20 grams). However, since a single aircraft data transmission cable has a weight of $32 \mathrm{~g} / \mathrm{m} \mathrm{[26]} \mathrm{and} \mathrm{has} \mathrm{a} \mathrm{length} \mathrm{of} \mathrm{several} \mathrm{meters,} \mathrm{the}$ proposed power harvesting system can be applicable for aerospace applications. 


\section{Conclusions}

This paper focused on improving the performance of thermo-electric generators (TEGs) with heatsinks for low-power wireless SHM systems. With reference to a classic commercial heatsink with cylindrical pins, an optimisation process was here performed in order to retrieve the optimum pin shape and pin number. In this process, both pin height and heatsink volume were maintained constant and manufacturing limitations were taken into account. In order to reduce the manufacturing process and costs, two basic pin cross-section shape, rectangular (new) and circular (classic), were analysed and the pin external surface was maximised leading to an increase of the heatsink convective thermal exchange. By assuming a constant height $(20 \mathrm{~mm})$ and volume $\left(68.2 \mathrm{~mm}^{3}\right)$ of the pin, the circular pin section with a radius of $1 \mathrm{~mm}$ (minimum dimension allowed from manufacturing) showed an external surface of $126 \mathrm{~mm}^{2}$, whilst the rectangular pin section with thickness of 1 $\mathrm{mm}$ and a length of $3.2 \mathrm{~mm}$ increased up to $165 \mathrm{~mm}^{2}$. In the case of rectangular pin shape, a pin length of $4 \mathrm{~mm}$ was obtained as a result of the optimisation process, so that a new study was carried out to calculate the number of pins necessary to match the reference heatsink volume. Although the reference heatsink was composed of 25 pins, leading to a total external surface of $3140 \mathrm{~mm}^{2}$, the new pin heatsink showed an augmented exchange area of $3921 \mathrm{~mm}^{2}$ with only 19 pins. Two new pin arrangements, aligned and mixed, were studied through numerical CFD thermal analyses in order to select the optimal configuration in terms of the cooling effect on the TEG. TEG hot face temperature was set to $100^{\circ} \mathrm{C}$, whilst the surrounding environment was set at a temperature of $25^{\circ} \mathrm{C}$ with natural convection as heat transfer between air and heatsink. Numerical results showed that a TEG temperature difference $\Delta T$ of $22.7^{\circ} \mathrm{C}$ was achieved using the heatsink with rectangular pin mixed disposition. Such a temperature difference value was enhanced of $0.7^{\circ} \mathrm{C}$ with respect to the aligned rectangular pin heatsink case and $4{ }^{\circ} \mathrm{C}$ with respect to the classic cylindrical heatsink. Thus, the rectangular pin mixed disposition heatsink was chosen as novel heatsink. Moreover, since TEG internal resistance and Seebeck coefficient were known, power output could be calculated for every load condition. The maximum power output, depending on temperature difference, resulted to be increased by the new heatsink $(11.6 \mathrm{~mW})$ in comparison with the aligned pin heatsink $(10.9 \mathrm{~mW})$ and the classic heatsink $(7.9 \mathrm{~mW})$. The two heatsinks (classic and novel) were manufactured so that CFD simulation results could be validated through a number of experiments. The improvement due to the new heatsink was confirmed as the temperature difference resulted to be raised from $17.7^{\circ} \mathrm{C}$ to $20^{\circ} \mathrm{C}$. Accordingly, maximum power output was increased from $7.3 \mathrm{~mW}$ to $8.9 \mathrm{~mW}$. However, both experimental temperature differences and power outputs resulted to be lower than numerical results because CFD simulations did not consider heat transfer loss due to manufacturing defects. A different manufacturing process, such as casting, can lead to a TEG cooling performance improvement that is supposed to be greater in the new heatsink set-up, where the $\Delta T$ drop resulted to be higher. Experimental campaign was extended as the hot plate temperature was varied between $50^{\circ} \mathrm{C}$ and $150^{\circ} \mathrm{C}$, with a step of $25^{\circ} \mathrm{C}$ in order to evaluate the effect of input temperature on TEG-heatsink assembly. The increase of hot 
temperature led to a linear increase of temperature difference and, as consequence, a quadratic increase of maximum power output. At every hot plate temperature, the new heatsink, compared to a classic heatsink with same weight, showed a higher cooling performance. In the last part of this work, two novel heatsinks were combined in a novel hybrid configuration so that the TEG could reach operative SHM power requirements of tens of $\mathrm{mW}$. A number of experiments was carried out and results showed that placing two heatsinks on a bare copper sheet allowed to reach a TEG temperature difference of $29.3^{\circ} \mathrm{C}$ leading to a maximum power output of $20.1 \mathrm{~mW}$. Hence, PGS were used to enhance heat transfer in the new heatsink configuration. A PGS was placed between copper sheet and heatsinks and TEG $\Delta T$ increased to $29.8^{\circ} \mathrm{C}$ so that the maximum power output was $20.5 \mathrm{~mW}$. On the other hand, placing a PGS between copper sheet and TEG increased even more these two parameters that reached $30.4^{\circ} \mathrm{C}$ and $21.4 \mathrm{~mW}$, respectively. The generated energy, regulated by a power management system, can be considered enough to feed a wireless SHM system for aerospace applications. Further, since the proposed TEG-heatsink assembly is very adaptable, it can also be tailored to other uses such as biomedical and military applications.

\section{References}

[1] Khaligh, A., Onar, O.C., 2010. “Energy Harvesting”. CRC Press, pp. 101-159.

[2] Boccardi, S., Callá, D.B., Ciampa, F. Meo, M., 2018. Nonlinear elastic multi-path reciprocal method for damage localisation in composite materials, Ultrasonics 82, pp. 239-245.

[3] De Simone, M. E., Ciampa, F., Boccardi, S., Meo, M., 2017. Impact source localisation in aerospace composite structures, Smart Materials and Structures 26(12), p. 125026.

[4] Scarselli, G., Nicassio, F., Pinto, F., Ciampa, F., Iervolino, O., Meo, M., 2016. A novel bistable energy harvesting concept, Smart Materials and Structures 25, p. 055001 .

[5] Erturk, A., Inman, D.J., 2011. Broadband piezoelectric power generation on high-energy orbits of the bistable Duffing oscillator with electromechanical coupling, Journal of Sound and Vibration 330, pp. 2339-2353.

[6] Roundy, S., Steingart, D., Frechette, L., Wright, P., Rabaey, J., 2004. "Power sources for wireless sensor networks," International Conference on Embedded Wireless Systems and Networks. Madrid, Spain, pp. 1-17.

[7] Ding, L.C., Akbarzadeh, A., Date, A., 2016. Performance and reliability of commercially available thermoelectric cells for power generation, Applied Thermal Engineering 102, pp. 548-556.

[8] Nakayama, W., 1986. Thermal management of electronic equipment: A review of technology and research topics, Applied Mechanic Reviews 39(12), pp. 1847-1868.

[9] Ndao, S., Peles, Y., Jensen, M.K.,2014. Effects of pin fin shape and configuration on the single-phase heat transfer characteristics of jet impingement on micro pin fins, International Journal of Heat and Mass Transfer 70, pp. 856-863.

[10] Bouknadel, A., Rah, I., El Omari, H., El Omari, H., 2014. "Comparative Study of Fin Geometries for Heat Sinks in Natural Convection,” International Renewable and Sustainable Energy Conference. Ouarzazate, Morocco, eds IEEE, pp. 723-728.

[11] Hirasawa, T., Kawabata, K., Oomi, M., 2005. Evolution of the Heatsink Technology, Furukawa Review 27, pp. 25-29.

[12] Elghool, A., Basrawi, F., Ibrahim, T.K., Ibrahim, H., Idris, D.M.N.D., 2017. A review on heat sink for thermo-electric power generation: Classifications and parameters affecting performance, Energy Conversion and Management 134, pp. 260-277. 
[13] Wang, C.C., Hung, C.I., Chen, W.H., 2012. Design of heat sink for improving the performance of thermoelectric generator using two-stage optimization, Energy 39, pp. 236-245.

[14] Pearson, M.R., Eaton, M.J., Pullin, R., Featherston, C.A., Holford, K.M., 2012. “Energy harvesting for aerospace structural health monitoring systems,” Journal of Physics: Conference Series 382(1), pp. 20-25.

[15] Bai, S., Lu, H., Wu, T., Yin, X., Shi, X., Chen, L., 2014. Numerical and experimental analysis for exhaust heat exchangers in automobile thermoelectric generators. Case Studies in Thermal Engineering 4, pp. 99-112.

[16] Bhutta, M.M.A., Hayat, N., Bashir, M.H., Khan, A.R., Ahmad, K.N., Khan, S., 2012. CFD applications in various heat exchangers design: A review, Applied Thermal Engineering 32, pp. 1-12.

[17] Junaidi, M.A.R., Rao, R., Sadaq, S.I., Ansari, M.M., 2014. Thermal Analysis of Splayed Pin Fin Heat Sink, International Journal of Modern Communication Technologies \& Research 2, pp. 48-53.

[18] Peltier, J.C.A., 1834. “Nouvelles expériences sur la caloricité des courants électriques”. Annales de Chimie et de Physique, vol. 56, pp. 371-386.

[19] Seebeck, T.J., 1826. “Ueber die magnetische Polarisation der Metalle und Erze durch Temperaturdifferenz”. Annalen der Physik, vol. 82, pp. $253-286$.

[20] Neamen, D.A., 2012. "Semiconductor physics and devices: basic principles". McGraw-Hill Education, pp. 103-148.

[21] Sanz Martinez, P.T., Cortes, D.F., 2014. Aircraft engine supporting pylon, US 8740138 B2.

[22] Bahadur, R., Bar-Cohen, A., 2005. Thermal Design and Optimization of Natural Convection Polymer Pin Fin Heat Sinks, IEEE Transactions on Components and Packaging Technologies 28(2), pp. 228-246.

[23] Boussinesq, J., 1903. "Théorie analytique de la chaleur: mise en harmonie avec la thermodynamique et avec la théorie mécanique de la lumière”. GauthierVillars, vol. 2.

[24] Zhou, D., Ha, D.S., Inman, D.J., 2010. Ultra low-power active wireless sensor for structural health monitoring, Smart Structures and Systems 6(5-6), pp. 675687.

[25] Norton, D. E., Podell, A. F., 1975. Transistor amplifier with impedance matching transformer, US 3891934.

[26] Daumand, T., Nexans, 2014. Data transmission cable intended for the aeronautical industry. U.S. Patent 20,140,299,348. 